\title{
Certifiable Disability in First Episode Schizophrenia: The Role of Adherence to Antipsychotic Treatment
}

\author{
Channaveerachari Naveen Kumar · Jagadisha Thirthalli • \\ Mounesh Yadav • Bangalore N. Gangadhar • \\ Mathew Varghese · Linda B. Cottler
}

Received: 24 August 2014/Accepted: 23 October 2014/Published online: 7 November 2014

(C) Springer India Pvt. Ltd. 2014

\begin{abstract}
The incidence rate of schizophrenia in India is about 3 per 10,000 per year-every year around 200,000 individuals get afflicted with it. Patients with disability greater than $40 \%$ are eligible for disability benefits from the government of India. However, it is not known as to what proportion of patients with new-onset schizophrenia would be eligible for this. At the National Institute of Mental Health and Neurosciences, Bangalore, 80 patients with FES were studied prospectively. Diagnosis was confirmed using the Computerized Diagnostic Interview Schedule Version4. Disability was assessed after about 2 years of follow-up using the Indian Disability Assessment and Evaluation scale. Those with $40 \%$ or more disability on the IDEAS were categorized as 'disabled'. 'Non-adherence' was defined as a continuous 3 months period of not taking antipsychotic medication. At the end of 2 years of follow-
\end{abstract}

C. N. Kumar · J. Thirthalli $(\bowtie) \cdot$ M. Yadav •

B. N. Gangadhar · M. Varghese

Department of Psychiatry, National Institute of Mental Health and Neurosciences, Hosur Road, Bangalore 560029, India

e-mail: jagatth@yahoo.com

C. N. Kumar

e-mail: cnkumar1974@gmail.com

M. Yadav

e-mail: mounesh.yadav@gmail.com

B. N. Gangadhar

e-mail: kalyanybg@yahoo.com

M. Varghese

e-mail: mat.varg@yahoo.com

L. B. Cottler

College of Public Health and Health Professions and College

of Medicine, University of Florida, 2004 Mowry Drive,

PO Box 100231, Gainesville, FL 32611, USA

e-mail: lbcottler@ufl.edu up, $19 / 80(23.8 \%)$ of the 80 patients had met the criterion for certifiable disability. Only $3(9.7 \%)$ of the 31 patients who were adherent to medication met this criteria, vis-à-vis $16(32.7 \%)$ of the 49 who were non-adherent $(p=0.02$; odds ratio $=4.52 ; 95 \%$ CI: $1.2-17.2)$. Older age and higher psychopathology score were also associated with disability. Psychopathology emerged as a significant predictor of disability after controlling for the effects age and treatment adherence. Only a small proportion of patients with FES remain disabled if they are adherent to medications. Efforts towards enhancing adherence could be cost-effective from a public health perspective.

Keywords Disability · First episode schizophrenia · Adherence $\cdot$ Antipsychotics

\section{Background}

Schizophrenia is one among the most disabling of all medical disorders accounting for 15.2 million years of disability adjusted life years lost (DALYs) in low and middle income countries [1]. Negative symptoms, longer duration of illnesses, male sex, treatment non-adherence, greater baseline psychopathology were among the predictors of disability among schizophrenia patients as deciphered in a recent review on disability in schizophrenia [2].

In India, the Government recently extended the welfare measures, meant for citizens with disability, to individuals with disability because of mental illnesses too [3]. These welfare measures include monthly disability pension, travel concession in trains and buses, income tax exemption benefits to the family caregivers, reservation in employment, educational allowances, etc. In order to assess disability and certify the beneficiaries, the Indian Government has adopted 
a scale, IDEAS [Indian Disability Evaluation and Assessment Scale; [4]. Those with $40 \%$ more disability are certified to have disability and would be eligible for availing the welfare benefits.

Most studies examining the disability in schizophrenia have included patients who had suffered several years of illness. An important goal of early intervention of schizophrenia is limitation of the disability caused by it. Symptomatic recovery in first episode schizophrenia (FES) is very promising, with up-to $96 \%$ of patients experiencing symptomatic remission from their episodes [5-7]. However, literature examining the disability status of patients with FES is limited.

The incidence of schizophrenia in India is about 0.3 per 1,000 [8, 9]. Approximately about 300,000 individuals develop schizophrenia every year in India. In order to effectively scale up services for these patients, it is imperative to understand as to what proportion of the new onset patients would fall into the 'disabled' category. We had an opportunity to examine this in a cohort of first episode schizophrenia (FES) patients. In this paper we describe the proportion of FES patients who would qualify for disability after about 2 years of initiating treatment.

\section{Materials and Methods}

Patients and Setting

One hundred nineteen consecutive out-patients with schizophrenia or schizophreniform disorders, who attended the outpatient services of the National Institute of Mental Health and Neurosciences (NIMHANS), Bangalore, were recruited as part of study that examined the effect of duration of untreated psychosis (DUP) on outcome [10].The patients had not received any antipsychotic medications before recruitment into the study. We used the Computerized Diagnostic Interview Schedule for DSM-IV (CDIS-IV) to confirm the diagnosis [11]. Those with comorbid psychiatric diagnoses, including substance use disorders (except nicotine), organic brain disorder, and mental retardation were excluded.

\section{Assessments}

Apart from CDIS-IV, the following assessments were conducted.

\section{Disability}

IDEAS was used to assess the psychiatric disability. IDEAS consists of four items viz: self-care, interpersonal activities (social relationships), communication and understanding, and work. Each item is scored between 0 and 4, adding scores on 4 items gives the 'total disability score'. IDEAS has good internal consistency (alpha $=0.8682$ ), good criterion validity and face validity and criterion validity. IDEAS is the official instrument notified by the government of India to qualify patients for disability benefits. IDEAS was administered by the project social worker at the end of 2 years of follow-up. He was trained in its administration by JT. Those with total IDEAS score of 7 or more were categorized as 'disabled' and those less than seven were categorized as 'not-disabled' for the purpose of this study as is done in our previous research [12].

\section{Symptoms}

The positive and negative syndrome scale (PANSS; [13]) was used to assess the severity of symptoms at both baseline and regular intervals at each follow-up (follow-up was done once in 2 months). For the purpose of this paper, PANSS rating at the baseline and at the end of 2-year follow-up point was examined. The raters were trained in the use of PANSS using training videos. The inter-rater reliability was assessed between them for the sub-scores and total score of PANSS of eight patients who were not included in the study. Reliability was found to be excellent, with an intra-class correlation of $0.92(p<0.001)$.

\section{Treatment Adherence}

Details regarding treatment adherence was obtained at each clinical follow-up, which ranged from once in 2 months to once in 4 months, from the patients' self-report as well as from the caregivers who lived with the patient and supervised their medications. 'Non-adherence' was defined as a continuous 3 months period of not taking antipsychotic medication at the time of assessment of disability.

\section{Treatment and Follow-up}

After their initial evaluation and through the follow-up period, patients received the following: risperidone $(n=99)$, olanzapine $(n=11)$, fluphenazine depot injections $(n=7)$, chlorpromazine $(n=2)$, haloperidol $(n=2)$, and flupenthixol depot injections $(n=2)$. Psychoeducation sessions, which covered topics of causes, clinical features, course, and treatment of schizophrenia were also, part of the management. Apart from this, no other structured psychosocial intervention was provided.

At the end of average 2 years of follow-up, IDEAS data was available for 80 patients and PANSS data was available for 79 patients.Following were the reasons for not having the remaining data: death of the patients $(n=3)$, non-traceability of patients $(n=37)$. 
Table 1 Comparison of Patients with and without disability

\begin{tabular}{|c|c|c|c|c|}
\hline Variable & $\begin{array}{l}\text { Disabled } \\
\text { group } \\
(n=19)\end{array}$ & $\begin{array}{l}\text { Not-disabled } \\
\text { group } \\
(n=61)\end{array}$ & $\mathrm{T} / \chi^{2}$ & $p$ value \\
\hline Age & $26.3(8.0)$ & $31.9(8.9)$ & 2.2 & 0.03 \\
\hline \multicolumn{5}{|l|}{$\operatorname{Sex}[n(\%)]$} \\
\hline Males & $12 / 50(24.0)$ & $38 / 50(76.0)$ & 0.005 & 0.95 \\
\hline Females & $7 / 30(23.3)$ & 23/30 (23.8) & & \\
\hline $\begin{array}{l}\text { Duration of } \\
\text { untreated } \\
\text { psychosis } \\
\text { (weeks) }\end{array}$ & $107.2(161.7)$ & $93.5(114.3)$ & -0.4 & 0.70 \\
\hline $\begin{array}{l}\text { Baseline total } \\
\text { PANSS }\end{array}$ & $64.1(15.7)$ & $59.8(13.2)$ & -1.2 & 0.24 \\
\hline $\begin{array}{l}\text { Total PANSS at } \\
\text { the end of } \\
2 \text { years } \\
\text { follow-up }\end{array}$ & $80.8(25.9)$ & $44.83(14.6)$ & -7.6 & $<0.01$ \\
\hline $\begin{array}{l}\text { Total IDEAS at } \\
\text { the end of } \\
2 \text { years of } \\
\text { follow-up }\end{array}$ & $9.8(2.7)$ & $1.4(1.7)$ & -16.2 & $<0.01$ \\
\hline \multicolumn{5}{|l|}{ Adherence pattern } \\
\hline Present & 3/19 (15.8) & 28/61 (45.9) & 5.5 & 0.02 \\
\hline Absent & $16 / 19(84.2)$ & $33 / 61(54.1)$ & & \\
\hline
\end{tabular}

\section{Statistical Analysis}

We used independent sample- $t$ test to analyze continuous variables, $\chi^{2}$ test was used to analyze discrete variables. Repeated Measures Analysis of Variance (RMANOVA) was used to test the outcome differences between the 'adherent' and 'non-adherent' groups. Logistic regression was used to explore predictors of disability using disability status as the dependent variable and variables associated with disability in the univariate analysis as independent variables.

\section{Ethical Considerations}

The study on DUP and outcome of FES was approved by the NIMHANS ethical committee. The subjects were recruited after obtaining the written informed consent from them as well as from their family caregivers. This paper is an offshoot of this data.

\section{Results}

The mean (SD) age of the sample was 30.7(9.0) years. There were $50(62.5 \%)$ males; mean (SD) duration of education was $8.0(5.3)$ years, $33 / 80(41.2 \%)$ were married, mean(SD)

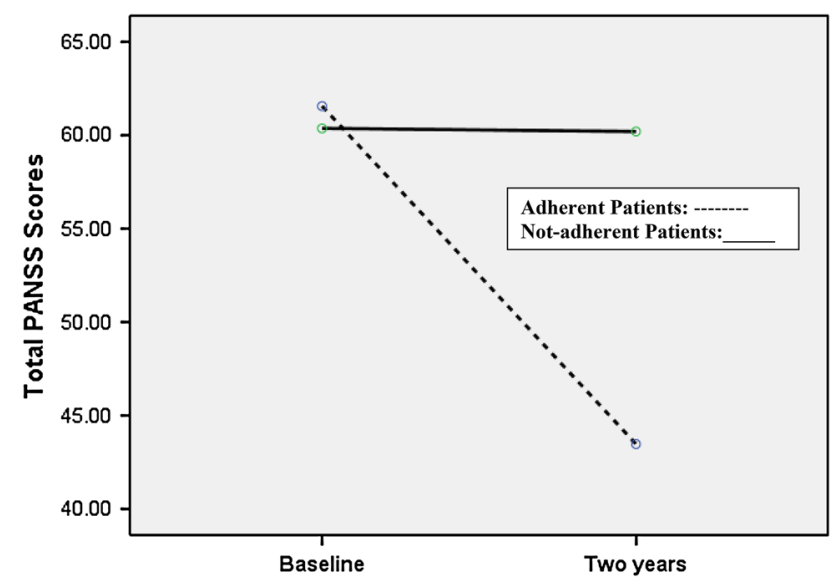

Fig. 1 Changes in PANSS scores over the course of 2 years; PANSS Positive and Negative Syndrome Scale. Group $\times$ time interaction: $F=11.4 ; p<0.01$

duration of untreated psychosis was 96.5(125.1) weeks, total baseline mean (SD) PANSS was 60.8(13.9) and total mean (SD) PANSS at the end of follow-up was 53.5(23.6).

At the end of follow-up period, overall, 19 of the 80(23.8\%) patients had score of 7 or more on the IDEAS, i.e., had certifiable disability. Table 1 shows the comparison of patients with and without disability at the end of 2 years. As can be made out, the disabled group had significantly more severe symptoms at the end of 2 years of follow-up. Only three of the 31(9.7\%) adherent patients and 16 of 49(32.7\%) not-adherent patients were disabled [adjusted odds ratio $=4.52 ; 95 \% \mathrm{CI}: 1.2-17.2 ; p=0.02$ ]. Of the nine patients on depot injections, six (66.6\%) patients were adherent and of these six patients, two $(33.3 \%)$ were disabled. Of the three non-adherent patients, two $(66.6 \%)$ were disabled.

In adherent patients, total mean (SD) PANSS score changed from 61.5(12.3) at baseline to 43.5(15.0) at follows up; these figures were 60.4(14.9) and 59.6(25.8) for non-adherent patients; group $\mathrm{X}$ occasion interaction effect in RMANOVA was significant (Fig. $1 ; \quad F=11.4$; $\mathrm{df}=1,1 ; \quad p<0.01), \quad$ indicating significantly greater reduction of symptoms among the adherent patients. There was a significant positive correlation between the symptoms severity and the severity of disability at the end of 2 years (Pearson's $r=0.74 ; p<0.01$ ).

Logistic regression was used with 'disability' status as dependent variable and adherence,ageand total PANSS score at follow-up as independent variables. The model was significant at $p<0.01$. Only total PANSS score remained as a significant predictor of disability status (adjusted odds ratio $=1.07 ; 95 \%$ CI: $1.03-1.13$ ), suggesting that the influence of adherence on disability was mediated by its influence on psychopathology. 


\section{Discussion}

The most important finding of this study is that among treatment-adherent FES patients the proportion of those with certifiable disability was only about $10 \%$. Nonadherence was associated with approximately five times higher rates of being 'disabled' than those who remain adherent to their medications. Notably, apart from psychoeducation, no other structured psychosocial intervention was provided. In this background, ensuring treatment adherence in itself may be sufficient for a considerable number of patients to remain disability-free. From a publichealth perspective, ensuring treatment adherence could become a cost-effective way of reducing disability associated with schizophrenia.

Prospective design, diagnosis using a structured interview schedule (CDIS-IV) by a trained psychiatrist and standardized assessments for measuring psychopathology and disability are the strengths of the study. Certain limitations are as follows: Firstly, we did not use any structured assessment measure for treatment adherence; we relied upon reports from patients and their relatives who supervised their medications. It may be noted that none of the contemporary methods of assessing medication adherence is foolproof [14]; self and family reports about adherence have been reliably used in earlier studies $[15,16]$. In Indian socio-cultural milieu, report from the family members, who supervise medication adherence, provides fairly reliable information. Further, we used fairly 'liberal' criteria to define non-adherence: it is known that missing medications even for shorter durations of time could result in exacerbation of symptoms. Secondly, we were not able to obtain data of all patients at the end of 2 years follow-up; it is difficult to speculate as to how this could have influenced the overall results. Thirdly, as this was a secondary analysis of an original study with a different aim, we did not have baseline disability data. Finally, other factors that could impact upon disability (e.g., family support) were not assessed.

It is interesting to note that though disability was more likely in the non-adherent patients, about $70 \%$ of them were not disabled. Experiencing remission with antipsychotics is a common cause of non-adherence [17, 18] and we speculate that a proportion of patients who were nonadherent could be those experiencing remission. Less than $20 \%$ of patients with schizophrenia remain without experiencing relapse [19]; a longer-term follow up could have, arguably found a higher proportion of disabled patients due to repeated relapses. Psychopathology was significantly associated with disability status. The results of logistic regression analysis suggest that the influence of adherence on disability is possibly mediated through its influence on symptoms.
In conclusion, only about $10 \%$ of first episode schizophrenia patients experience substantial disability if they are adherent to antipsychotic treatment. In the background of limited professional manpower in low-and-middle-income countries, efforts towards ensuring adherence could be a cost-effective means of limiting disability. Manpowerintensive psychosocial interventions could be reserved for those who remain disabled despite adherence to medications.

Acknowledgments This work was supported by the Re-entry grant awarded to Dr. Jagadisha Thirthalli by the Fogarty International Center-ICOHRTA Training Grant \# D43TW5811 (L. B. Cottler, PI).

\section{References}

1. Alvarez-Jimenez M, Parker AG, Hetrick SE, McGorry PD, Gleeson JF. Preventing the second episode: a systematic review and meta-analysis of psychosocial and pharmacological trials in first-episode psychosis. Schizophr Bull. 2011;37:619-30.

2. Thirthalli J, Kumar CN. Stigma and disability in schizophrenia: developing countries' perspective. Int Rev Psychiatry. 2012;24:423-40.

3. Persons with Disabilities Act 1995 [database on the Internet]. http://socialjustice.nic.in/pwdact1995.php.

4. Persons with Disabilities Act. http://socialjustice.nic.in/policie sacts3.php. Accessed 20 Aug 2014.

5. Sanger TM, Lieberman JA, Tohen M, Grundy S, Beasley C Jr, Tollefson GD. Olanzapine versus haloperidol treatment in firstepisode psychosis. Am J Psychiatry. 1999;156:79-87.

6. Lieberman JA, Tollefson G, Tohen M, Green AI, Gur RE, Kahn $\mathrm{R}$, et al. Comparative efficacy and safety of atypical and conventional antipsychotic drugs in first-episode psychosis: a randomized, double-blind trial of olanzapine versus haloperidol. Am J Psychiatry. 2003;160:1396-404.

7. Schooler N, Rabinowitz J, Davidson M, Emsley R, Harvey PD, Kopala L, et al. Risperidone and haloperidol in first-episode psychosis: a long-term randomized trial. Am J Psychiatry. 2005;162:947-53.

8. Wig NN, Varma VK, Mattoo SK, Behere PB, Phookan HR, Misra $\mathrm{AK}$, et al. An incidence study of schizophrenia in India. Indian J Psychiatry. 1993;35:11-7.

9. Rajkumar S, Padmavathi R, Thara R, Menon MS. Incidence of schizophrenia in an urban community in madras. Indian J Psychiatry. 1993;35:18-21.

10. Thirthalli J, Channaveerachari NK, Subbakrishna DK, Cottler LB, Varghese M, Gangadhar BN. Prospective study of duration of untreated psychosis and outcome of never-treated patients with schizophrenia in India. Indian J Psychiatry. 2011;53:319-23.

11. Robins LN Cottier LB, Bucholz KK, Comptom WM, North CS, Rourke KM (2000) Diagnostic interview schedule for the DSMIV (DIS-IV).

12. Thirthalli J, Venkatesh BK, Kishorekumar KV, Arunachala U, Venkatasubramanian G, Subbakrishna DK, et al. Prospective comparison of course of disability in antipsychotic-treated and untreated schizophrenia patients. Acta Psychiatr Scand. 2009;119:209-17.

13. Kay SR, Fiszbein A, Opler LA. The positive and negative syndrome scale (PANSS) for schizophrenia. Schizophr Bull. 1987;13:261-76.

14. Farooq S, Naeem F. Tackling nonadherence in psychiatric disorders: current opinion. Neuropsychiatr Dis Treat. 2014;10: 1069-77. 
15. Subotnik KL, Nuechterlein KH, Ventura J, Gitlin MJ, Marder S, Mintz J, et al. Risperidone nonadherence and return of positive symptoms in the early course of schizophrenia. Am J Psychiatry. 2011;168:286-92.

16. Suresh KK, Kumar CN, Thirthalli J, Bijjal S, Venkatesh BK, Arunachala U, et al. Work functioning of schizophrenia patients in a rural south Indian community: status at 4-year follow-up. Soc Psychiatry Psychiatr Epidemiol. 2012;47:1865-71.

17. Yadav MTJ, Kumar CN, Varghese M, Cottler LB. Reasons for non-adherence to antipsychotic medications in first episode schizophrenia in India: results from a Prospective Study. Bangalore, India: World Congress of the World Association for Psychosocial Rehabilitation; 2009.

18. Thara R, Rajkumar S. A study of sample attrition in follow up of schizophrenia. Indian J Psychiatry. 1990;32:217-22.

19. Robinson D, Woerner MG, Alvir JM, Bilder R, Goldman R, Geisler S, et al. Predictors of relapse following response from a first episode of schizophrenia or schizoaffective disorder. Arch Gen Psychiatry. 1999;56:241-7. 